This item was submitted to Loughborough's Research Repository by the author.

Items in Figshare are protected by copyright, with all rights reserved, unless otherwise indicated.

\title{
Drug policy governance in the UK: lessons from changes to and debates concerning the classification of cannabis under the 1971 Misuse of Drugs Act
}

\section{PLEASE CITE THE PUBLISHED VERSION}

http://dx.doi.org/10.1016/j.drugpo.2014.02.001

\section{PUBLISHER}

(C) Elsevier

\section{VERSION}

AM (Accepted Manuscript)

\section{PUBLISHER STATEMENT}

This work is made available according to the conditions of the Creative Commons Attribution-NonCommercialNoDerivatives 4.0 International (CC BY-NC-ND 4.0) licence. Full details of this licence are available at: https://creativecommons.org/licenses/by-nc-nd/4.0/

\section{LICENCE}

CC BY-NC-ND 4.0

\section{REPOSITORY RECORD}

Monaghan, Mark P.. 2019. "Drug Policy Governance in the UK: Lessons from Changes to and Debates Concerning the Classification of Cannabis Under the 1971 Misuse of Drugs Act". figshare.

https://hdl.handle.net/2134/21320. 
Elsevier Editorial System(tm) for International Journal of Drug Policy

Manuscript Draft

Manuscript Number: DRUGPO-D-13-224

Title: Drug Policy Governance in the UK: Lessons from changes to and debates concerning

the classification of cannabis under the 1971

Misuse of Drugs Act

Article Type: Special Issue: Governance of Drug Policy

Keywords: Policy, Governance, Misuse of Drugs Act, Evidence-Based Policy

Corresponding Author: Dr. Mark Monaghan, PhD

Corresponding Author's Institution: University of Leeds

First Author: Mark Monaghan, PhD

Order of Authors: Mark Monaghan, PhD

\section{Background}

Drugs policy is made in a politically charged atmosphere. This is often not seen to be conducive to the ideals of evidence-based policymaking. In the UK over recent years the efficacy of the 1971 Misuse of Drugs Act (MDA) has been one of the most widely discussed and debated areas of UK drug policy. Since inception, the MDA 1971 has remained relatively stable with very few drugs moving up or down the scale and until recently, and with very few exceptions, there has been little public debate on the nature of the system. This changed in the run up to the cannabis reclassification in 2004 from class B to class C, through the reverse of this decision in 2009 and the fallout between the Government of the time and leading members of the Advisory Council of the Misuse of Drugs.

\section{Methods}

Based on wide-ranging survey of the literature and secondary analysis of various official publications and academic commentaries, this paper considers what the cannabis episode can tell us about the current state of UK drug policy governance.

\section{Results}

Previous research on drug policy governance has suggested that policy goals should be clearly articulated so as to avoid confusion over what constitutes evidence, decision-makers should be 'evidence-imbued' and there should be widespread consultation with, and transparency of, stakeholder engagement. The interpretation here is that recent changes to cannabis legislation reveal that these aspects of good governance were called into question although there were fleeting moments of good practice.

\section{Conclusion}

The use of evidence in drug policy formulation continues to be bedevilled by political stalemate and reluctance to countenance radical reform. Where evidence does play a role it tends to be at the margins. There are, however, potential lessons to be learned from other policy areas but this requires a more pragmatic attitude on behalf of decision-makers.

\section{Introduction}


"Science can, indeed, I would argue must, be the prime mediator of policy if we are to minimize the harms of drugs, both medical and social, but science cannot deliver policy because that is the realm of politics" (Nutt, 2010 p.1154)

In the UK (and elsewhere) drug policy is made in a politically charged atmosphere. Nowhere is this more apparent than in debates over the legal classification of substances. In the UK the legal classification of drugs is covered by the 1971 Misuse of Drugs Act (MDA). Since inception, the MDA has remained relatively stable with very few drugs moving up or down the scale. This changed in the run up to the cannabis reclassification from class B to class C in 2004 through the reverse of this decision in 2009 and with the subsequent fallout between the Government of the time and leading members of the Advisory Council of the Misuse of Drugs (ACMD), against whose advice the latter decision was taken.

The efficacy of the 1971 MDA has come to be one of the most widely discussed and debated areas of UK drug policy. Here a clash between science and politics is highly visible and debates are highly politicised. The media reporting of these debates has tended not to focus on the complex scientific deliberation and the evidence-base underpinning classification proposals, but on the political sensibilities of politicians who are labelled as liberal or illiberal on drug policy depending on attitudes towards classification and thus the extent that they are willing to be guided by evidence. Here the UK is not alone and nor is this a new development. Tieberghien and Decorte (2013) note similar themes in their discussion of recent changes in Belgian drugs policy. MacGregor (2013:227), meanwhile, demonstrates that the 'tension between evidence and values' has been a 'consistent theme' in drug policy formulation for some time.

In recent years, many governments and agencies have committed themselves to the process of designing, developing, implementing and evaluating policies with a strong research base. In essence, they have signed up to a programme of evidence-based policy making (EBPM). Although the research and policy connection has a long history, in the UK EBPM was closely with the election of the New Labour government in 1997. From the outset, the ideal of EBPM outlined by the New Labour government was beset with problems (see Head, 2010). Primary amongst these was the suggestion that policy-makers and politicians are influenced by factors other than the findings of research .Since the passing of the 1971 MDA, in public debate and discourse, drugs have taken on especial negative connotations being associated with incivility and vice. Consequently, drugs have been linked to the 'other' and have aroused passionate, value-driven debates over their perceived harms and dangers. As this is so, they are 'unlikely to be dealt with simply as matter of technocratic, evidence-based, scientific discourse' (MacGregor, 2013:226).

Oakley (2012) provides some for evidence for this comparing and contrasting the fluctuating fortunes of 2 major reports published in the 1960s, both authored by Baroness Wootton. The first Wootton Report on Cannabis legislation (Advisory Committee on Drug Dependence, 1968) was disowned by the government that had sponsored it', whereas the second report on alternatives to prison (Advisory Council on the Penal System, 1970), 'led directly to legislation establishing community service as an alternative to imprisonment, a sentence that is still part of penal policy today' (Oakley, 2012: 268). Unlike Wooton's Prisons 
report, Oakley suggests that the cannabis report dealt with a specific highly contentious issue that led to sensationalist reportage by the media of the day. In addition, the Cannabis report's findings took the form of a nuanced message that cannabis should not be legalised, but that it should be made distinct in law from other prohibited substances. This message was inconsistent with the ideological stance of key decision-makers at the time, especially Home Secretary James Callaghan. Similar themes, as we shall see, can be witnessed over 4 decades later.

The issue of cannabis classification gained prominence because it was linked to an increasing preoccupation amongst academics, policy makers and the public over the way that evidence is used, misused or unused in policy making. Policy-making that draws on and uses a broad evidence-base is seen to be a key component of good governance as outlined in a recent report by the UKDPC (Hamilton, et al, 2012) however, the primacy status of evidence in policy is questioned by the way that it cannot or should not interfere with the principles of democratic decision-making (HM Government, 2011). In short, the reversal of the decision to classify cannabis as a Class $C$ substance provides a critical case study in looking at the often fractious relationship between the role and use of evidence in decisionmaking and the principles of parliamentary democracy and how best to bridge this gap. With this in mind, the first section offers a brief overview of the way drugs are classified under 1971 MDA. This is followed by a look at more recent events relating to proposed changes to the drug classification system primarily relating to cannabis. Next, discussion turns to the link between the disputes over drug classification and how these relate to some of the principles of good governance outlined in previous research by the United Kingdom Drug Policy Commission (Hamilton, et al, 2012). The penultimate section turns towards some potential solutions. Finally, some concluding remarks are made.

\section{The 1971 MDA Drug Classification System}

The origins of the 1971 MDA can be traced to discussions in the run up to the 1961 United Nations Single Convention on Narcotic Drugs. The Single Convention aimed to standardise the control of narcotics across nations so that certain drugs could be used only for scientific, medical, and in some cases, industrial purposes. This was achieved by arranging drugs into schedules and applying appropriate controls based on their harm and toxicity. Any article in contravention of the convention was a punishable offence, with a custodial term for serious breaches (Fortson 2005). A defining feature of the MDA is its instigation of a strict classification system for scheduling drugs. Thus, in the UK drugs are placed in one of three categories, $\mathrm{A}, \mathrm{B}$ or $\mathrm{C}$ determined by the extent of relative harm their misuse is perceived to inflict on the individual and society. Indeed, as Levitt, et al. (2006:15) note Section 1.2 of the MDA states that drugs are divided between classes based on: (a) whether the drug is being misused; (b) whether it is likely to be misused and (c) whether the misuse in either case is having or could have harmful effects sufficient to constitute a social problem.

A further key component of the 1971 legislation was that it established Britain's first statutory expert advisory body on illicit drugs, the ACMD. Amongst their many functions, the ACMD continuously review the UK drug situation, paying particular attention to the misuse (or the potential thereof) of drugs by the public to the extent that they might be 
considered a social problem. This is mainly achieved through the production of detailed and rigorous evidence reviews. Their membership is made up from across the scientific, industrial and professional sectors, but most of their work concentrates on the pharmacological evidence-base for existing and emerging substances thus embedding science, research and expertise into the decision-making process. For most of its existence it was common practice for the government to accept and act upon the recommendations of the council, although in a very high-profile way this relationship has been tumultuous over recent years, highlighted in recent public debates about the classification of ecstasy, magic mushrooms ${ }^{i}$ and, primarily, cannabis within the MDA.

\section{The Changing Status of Cannabis in the MDA}

In the run up to the cannabis classification in 2004, evidence from a number of high-profile reports into the operation of the MDA had concluded that the current system had created some anomalies and that cannabis, in particular, was classified too high in class B (Police Foundation, 2000; Home Affairs Committee, 2002). The Police Foundation Report (2000) had particular significance suggesting that the downgrading of cannabis should be undertaken alongside more discretionary use of police warnings for cannabis possession offences. This coincided with the so-called 'Brixton experiment' which effectively introduced informal disposal and a formal on-the-spot warning for those caught in possession of cannabis. Against this backdrop, the then Home Secretary David Blunkett, told the Home Affairs Committee in October 2001 that he was 'minded' to downgrade cannabis and would seek advice from the ACMD on the possibility of reclassification. The ACMD (2002) reported back that cannabis should be reclassified. In July 2003, it was announced that on Parliamentary approval cannabis would be reclassified to a class $C$ drug, coming into force in January $2004^{\text {ii }}$.

In a broader discussion over the complexity of the evidence-base for the reclassification, Monaghan (2010) demonstrates how the reform of the UK cannabis laws was contingent on two main factors. The first was that reclassification would concentrate police resources on tackling the perceived high-levels of acquisitive crime associated with the problematic use of heroin and crack cocaine (May, et al, 2002). This was on the assumption that time would not be spent processing cannabis arrests unless there were aggravating factors such as consuming cannabis in the vicinity of legal minors, for instance, near a school. The second factor was that in terms of its toxicity or harmfulness, cannabis was not comparable with other class A or B drugs. Following the 2004 reclassification, academic and public attention was drawn to the (re)discovery of the link between the use of particularly high-strength strains of cannabis (skunk) and certain kinds of mental illness (Fergusson, et al., 2005; Arsenault, et al., 2004; Henquet, et al., 2004.).

A general mood of support from across the print media accompanied Blunkett's initial decision. However, Daly and Sampson (2012:271) demonstrate how in the aftermath of cannabis reclassification the tabloid press 'filled hundreds of column inches with exaggerated scare stories about the drug'. The ensuing panic reached a peak around 2007, but as early as 2002 the Daily Mail was reporting that cannabis use not only increased a user's chances of becoming mentally ill, but that it was also linked to violent behaviour. 
In March 2005, in the midst of the panic surrounding cannabis and primarily in response to warnings over skunk, the then Home Secretary Charles Clarke announced that the reclassification of cannabis implemented the previous year would be reviewed. Shortly after, the ACMD (2005) published a second review, stating that class C was appropriate, a decision accepted by Clarke. However, drug classification returned again to the media headlines in 2008. The new Prime Minister, Gordon Brown announced that, in light of continuing interest in the link between cannabis use and mental health, the classification of cannabis would once again be referred back to the ACMD. The ACMD (2008) reported back that although there was a consistent, but 'weak' association between cannabis use and the development of psychotic illness, they remained resolute that cannabis was correctly classified as a class $C$ substance. However, unlike in 2005, the Government ignored this advice and announced a reversal of the 2004 downgrading. Some informed observers argue this was done to demonstrate difference with the previous policies and to curry favour with certain parts of the media (see Daly and Sampson 2012; Dunn, 2013).

Whatever the underlying reasons, this was the origin of the dispute between Professor Nutt the then Chair of the ACMD and the New Labour government. This was to later escalate when in March 2009 the advisory council considered the legal status of ecstasy recommending a downgrading of its classification from class $A$ to $B$ ( $A C M D, 2009)$. The government's decision to seemingly ignore outright this advice led to a heated exchange between Nutt and the then Home Secretary, Jacqui Smith. Later in 2009 relations between members of the ACMD and the government further deteriorated. Alan Johnson, who by this time had replaced Smith as Home Secretary, accused Nutt of overstepping his remit and of 'campaigning against' government policy in a lecture delivered in July 2009 where Nutt claimed that based on the existing science both cannabis and ecstasy are less harmful than legal drugs such as alcohol and should, therefore, be downgraded. Nutt was subsequently dismissed from the ACMD leading to the resignation of five other members.

\section{The Politicisation of Drugs Policy and the Implications for Good Governance}

Debates over the nature of drugs policy are characterised by a non-trivial degree of politicisation and arouse emotions and thus sit alongside those of sentencing, police reform and other issues concerning the criminal-justice process. According to Loader and Sparks (2011), these debates have 'heated up' over recent years under the conditions of 'totemic toughness' (Stevens, 2011). The 'emotional context of drug policy' was also noted in the Royal Society of Arts (RSA) (2007) report into UK Drug policy:

...the demonization of drugs seems to us to have had a seriously detrimental effect on the quality of the policy discussion around illegal drugs. Cool deliberation and informed dialogue become difficult or even impossible, and public debate becomes overheated and polarised. Politicians often seem afraid to raise the subject in general terms lest they be quizzed in a hostile way about their own experiences (RSA, 2007:37).

Heavily politicised issues often conform to what Rittel and Webber, (1974) term 'wicked issues'. These are policy areas that defy neat solutions as there is little agreement on the nature of the problem in the first instance. In debates over the evidence-base for 
classification decisions, it is unclear whether the matter in hand is one of public health, law and order or morality, or indeed, all three. This can have serious implications for developing an evidence-base for policy (Monaghan, 2011) and in turn this impacts on effective governance in drug policy. To paraphrase, findings from the UKDPC research into the latter (Hamilton et al, 2012) revealed a number of issues that could ensure effective governance. These included: a) the key overarching goals of policy needed to be aspirational and realistic with cross-party support where possible, but clearly articulated so as to avoid confusion over what constitutes evidence in policy and how this is reconciled; b) in terms of policy delivery, evidence-imbued leadership is imperative in facilitating a central role for evidence use throughout the various stages of the policy process. Much rests, therefore, on political leader's attitudes towards evidence; c) widespread consultation with and transparency of stakeholder engagement is also vital including the role of the statutory advisory committee and the accountability mechanisms.

\section{Reconciling Evidence (From Opaque Policy Goals)}

Reconciling different types of evidence is a common theme in debates over the role of expertise in policy-making. The notion of professional equipoise is prominent in clinical medicine referring to a situation whereby practice is often divided over which treatment is the most effective to any given condition (e.g. Elwyn et al, 2000). Likewise, critics have pointed out that one of the true stumbling blocks to the realisation of evidence-based policy is the fact that the 'evidence' is rarely definitive. Indeed, a paradox of research is that the more heavily something is researched, the less there is convergence on points of agreement (e.g. Head, 2010).

The cannabis debates were no different. The evidence-base for the link between cannabis use and mental health is characterised by inconclusive data illustrated in the circumspect findings of the ACMD in relation to whether cannabis use causes mental illness (ACMD, $2002 ; 2005 ; 2008)$. Furthermore, throughout the classification debates, different perceptions and interpretations of the evidence competed for influence in the decisionmaking process. Evidence cited by David Blunkett in the reclassification ( $\mathrm{B}$ to $\mathrm{C}$ ) related to the relative toxicity of substances, more specifically the concomitant levels of Tetrahydrocannabinol (THC) - the main psychoactive ingredient - found in cannabis. This was heavily contested. For supporters of reclassification, evidence was referenced (e.g. ECMDDA, 2004) pointing to the fact that the purity and potency of cannabis obtained on street had not altered significantly over the previous two decades. For the critics, this was a fallacy and claims were made, mainly in the media, suggesting that levels of THC in contemporary genetically modified and hydroponic cannabis were anywhere between four and 20 times higher than the strains previously used (see Monaghan, 2011). A third significant perspective in this debate is that this is actually 'non-evidence', on the grounds that data on the effects of drugs on humans is woefully inadequate with significant gaps in the evidence-base on ingestion techniques, not to mention the reliability of using seized drugs as a gauge for all drugs in circulation.

Whatever the true reading, this example demonstrates that a mechanism for agreeing what counts as evidence in such debates was absent. When it comes to decisions over drug classification, evidence tends to be canvassed from various channels including the Police 
and law enforcement agencies, the scientific and expert communities, healthcare professionals and those with expertise on youth issues. Indeed, all the above are represented on the ACMD. What has been unclear, however, are the grounds on which some evidence is given primacy whilst other evidence is relegated to the periphery or ignored, leading to questions of transparency in the decision-making process and the sophistication of political leader's understandings of evidence.

\section{Evidence-Imbued Leadership and Political Attitudes to Evidence}

It would be easy to dismiss the political leadership of the New Labour era as having, what Weiss (1986) refers to as, a 'political' and 'tactical' attitude towards the use of evidence in policy. This is where evidence is carefully selected to support a pre-aligned policy position and where evidence can become subservient to the political realities of the day. Dean (2013) makes a compelling case in this regard. Indeed, we have seen how the political winds changed under Gordon Brown's premiership and that Home Secretaries Jacqui Smith and Alan Johnson were keen to act on cannabis by reverting it back to class $B$, in spite of the consistent guidance of the ACMD. This was achieved primarily by assigning causation rather than correlation to the long-standing issue of cannabis use and its links with mental illness. Blackman (2010) suggests that the Brown Government was attempting to reassert its commitment to prohibitionist policies, via the construction of a 'popular preventive.' Mills (2013) shows how in the history of cannabis policy decisions that ostensibly appear to be about cannabis are in reality about something else. With this in mind, it could be argued that reclassification to class B was less about cannabis per se and more about the new leadership establishing its authority.

It would be easy to make these claims, but this is not the only reading of the process, especially if a longer 'policy cycle' is considered. According to Sabatier and Jenkins-Smith (1993), it takes roughly a decade or more for a policy cycle to undergo a full revolution. If we apply this timeframe to the cannabis classification changes focusing on the period from 2000 to 2010, then we see that evidence was both used and ignored in the decision-making process. In the run-up to 2004, David Blunkett was heavily influenced by the evidence building up which pointed at the misclassification of cannabis as a class B substance. Alongside the toxicological evidence, he was particularly swayed by evidence of potential police efficiency savings. Charles Clarke, likewise, allowed himself to be guided by the advice of the experts in the area. Dean (2013) stresses that both Blunkett and Clarke had been afforded the opportunity to follow the evidence because of uncharacteristic moments of liberalism across the UK media spectrum in relation to cannabis. Whether or not this was the case, what the episode does indicate is that if a window of opportunity (Kingdon, 1984) is opened, politicians and decision-makers can be guided by evidence, but they will have to act as an adjudicator between different evidence bases. This will inevitably lead to accusations of political expediency when the evidence favoured does not chime with that favoured by particular groups, but this is quite different from pronouncing policies to be evidence free; an accusation that has been levelled at New Labour's handling of drug classification (MacDonald and Das, 2006).

\section{The Influence of Stakeholders in the Policy-Making Process}


Under contemporary forms of governance, policy decisions emerge, in part, out of the way a range of stakeholders coalesce around a particular position. Various groups arrive at their own interpretation of the evidence in order to propel decisions one way or another. Previous research has suggested that the evidence produced via expertise that fits in with the preconceived ideas of policy makers stands the best chance of being utilised in the decision-making process (e.g. Stevens, 2007). To elaborate, this requires consistency between experts and decision-makers in relation to a set of pre-existing social and cultural values. Ministers, governments and parliamentarians interpret or alight on evidence to align with pre-existing belief systems and it is also the case that scientists and experts likewise arrive and interpret evidence according to their underlying value systems. The cannabis episode, however, demonstrated that whilst evidence selection often follows this trajectory it is not a foregone conclusion. Where drug classification is concerned, the ACMD and government shared a similar perspective that the current system was broadly fit for purpose, but could be improved or 'rationalised' by minor tweaks to the legislation, which generally involved switching the classification of certain substances. It was only from 2009 onwards that this system started to visibly malfunction ${ }^{i i i}$ as the government chose to ignore the advice of its experts, first concerning cannabis and then ecstasy (Monaghan, 2011). A brief review of the debate over ecstasy classification demonstrates how well placed evidence producers and the evidence they supply can be side-lined in the decision-making process. In this scenario, the ACMD's (2009) scientific evidence stated that ecstasy is harmful, but that its relative harms were not akin to drugs such as heroin and crack cocaine. Indeed, they are significantly different if one considers the evidence base on toxicology, mortality rates, morbidity rates, and associated social harms (Nutt, et al., 2007; 2010). In the ecstasy case, a significant scientific stakeholder lobby advocated policy change. Although their arguments were presented in a concerted and largely united front, the scientific evidence was side-stepped by the government as a precautionary measure (Monaghan, et al, 2012). And on this basis, an opposing coalition advocating maintenance of the status quo came to the fore. Indeed, noteworthy support came from the Police and Superintendents Association who were quick to point out that classification should not be simply an academic or scientific exercise because it involves people's lives; a point sympathetically received by the Brown Government.

Drawing on the work of Habermas, (1975), Blackman (2010) suggests that the fallout over the drug classification between the Government and members of the ACMD signified a 'legitimation crisis' in the government's drug policy; where 'institutions are out of step with social and cultural values and government faces a loss of public confidence' (Blackman, 2010:348). This crisis, for Blackman, stemmed from the government's commitment to the war on drugs, despite the fact that some success appeared to be forthcoming with the more pragmatic policies being employed such as a reported downturn in cannabis prevalence in the population, as evidenced by various sweeps of the then British Crime Survey. In effect, Blackman maintains that the government resorted to 'the personalisation of substantive issues' (ibid.) where to give an appearance of toughness, the work of Nutt and colleagues was called into question.

\section{Potential Solutions for Drug Policy Governance}


Loader and Sparks (2011) comment how in the policy areas of crime and criminal justice policy, the relationship between science and politics has heated up over the past few decades and is now inherently combustible. Under such conditions, numerous attempts have been made to try and add 'coolant' to the debate. These include: a) creating a heightened role for the use of scientific expertise in policy under the aegis of evidencebased policy-making; b) creating a heightened awareness for academic work in policy circles by academics becoming policy advisors and; c) creating a heightened value for academic input into the policy process via academics taking positions within government as an observer-turned-player.

The difficulties entailed in the first solution have been covered in previous sections. Points ' $b$ ' and ' $c$ ' are closely aligned and here the role of the academic is broadly on as a knowledge broker. There are, however, relatively few accounts of academics working in policy departments. One notable exception is Stevens' (2011) account of his time working for a large government department concentrating on social policy and criminal justice issues. He found that civil servants were predisposed to using evidence in their decision-making, but 'use' referred to the development of particular policy narratives that they perceived would be politically palatable. Thus, evidence selection was contingent on the agents involved and how this may or may not aid their career progression. Evidence use was also ideological in that because research rarely produces definitive conclusions, the evidence that was selected had to fit with stories that did little to challenge the status quo. This was because these stories had reached the standard of public value.

Pandering to pre-existing political narratives has been a consistent theme in policy making in heavily politicised areas. Loader and Sparks (2011:110-113) demonstrate how much contemporary penal policy-making, because it is subject to democratic pressures, has the outcome of being 'excessive and illiberal'. Political deliberations over the length of time a terror suspect could be remanded in custody without trial are indicative. Pettit (2001) refers to this an 'outrage dynamic' whereby political decision-makers need to be totemically tough to be appealing to the electorate. Pettit's solution is to develop 'arms-length' institutions or bodies that can 'entrench professional' expertise in the decision-making process, but can be sheltered from the wider political discourse (Loader and Sparks, 2011:112). The example of monetary policy and the delegation of setting interest rates to independent central banks is frequently cited (Pettit, 2001; Lacey, 2008). The theory here is that certain policies benefit from being insulated from politics so that long-term solutions are prioritised over shortterm political gain.

The insulation solution, however, has proven to be imperfect. Devolving the decision to experts or even encouraging a space for the rational application of expertise to a policy problem could be seen as an abrogation of the principles of democracy and a step along the way to technocratic decision-making (Clarence, 2002). Weingert, (1999:154) suggests that under the conditions of technocracy, 'the politician becomes fully dependent on the expert. Politics is replaced by a scientifically rationalised administration' precisely because they have the requisite instrumental knowledge at their disposal and are thus in a more privileged position than their political counterparts. The promotion of technocratic decisionmaking was a la mode in France the nineteenth century and was closely linked to positivism. In Britain, as Delanty (1997:26) notes, 'science was not itself seen as capable of providing 
political leadership and this legacy remains In contemporary times, technocracy is rendered problematic on the grounds that it neglects the central issue that a certain amount of adjudication is always necessary between rival scientific findings.

A potential way forward may lie in giving due recognition to what Sanderson $(2009 ; 2010)$ has termed 'intelligent government'. Drawing on the ideas of Majone (1989) and Toulmin (2001) and writing from the perspective of Dewean pragmatism, Sanderson suggests that this requires a movement away from evidence-based policy making underpinned by instrumental rational action towards evidence-based policy as practical rational action. Underpinning this is the acknowledgement that policy-making in contemporary society must deal with complexity and uncertainty and must be as Sanderson (2009:713) notes a 'broader exercise in practical rationality' whereby communicative and deliberative processes ensure that ethical and moral concerns are addressed and all legitimate voices can be heard in coming to 'reasonable decisions'.

The headline event from the cannabis episode - the dismissal of Professor Nutt - suggests, however, that on balance in the area of drugs policy and with particular reference to the classification of substances, recent government decision-making is driven more by reactions to perceived public opinion than being proactively inspired by scientific and other expertise. That said, when a longer view is taken covering whole policy cycles, there may be some grounds for optimism to realise Sanderson's goal of viewing policy as practical rationality. It is, of course, salient for those extended the franchise to select candidates well versed in scientific as well as political decision-making (Henderson, 2012) and this will, therefore not be immediate.

\section{Conclusion}

The epigraph to this analysis on drug policy governance points to one of the most enduring dilemmas in political science and elsewhere; that is, how to bridge the gap between what Latour (2004) has referred to as the 'two houses of science and politics'. Such issues have taken on added resonance recently with the dismissal of Professor Nutt from his role of chair of the ACMD. Looking back at the record of the New Labour government (1997-2010) and bearing in mind the difficulties of treating this as a homogenous entity, it would be misleading to dismiss outright their efforts in developing drug classification policy with recourse to the evidence. This, however, is not to endorse their policy-making as a gold standard from which the current and future Government and government's elsewhere should learn. New Labour displayed an acute awareness of the benefits of evidence-imbued policy as well as a clear desire to ignore these principles for the sake of gaining political capital when it was deemed necessary. History will probably judge that the balance was skewed in favour of the latter

Where evidence-based policy making is concerned, the characteristics of good governance suggest that good policy development should make use of evidence in a manner that creates a mechanism for agreeing what counts as evidence in any given policy area and how this should be reconciled. There should be an even-handed approach to evidence by decision-makers and key accountability mechanisms. The cannabis episode is particularly revealing when analysed through this lens. It demonstrates how there is still much to do if 
these aspirations are to be realised in practice. UK drug policy making is fraught with political challenges where politicians make policy in an almost permanent state of electioneering, but evidence can and does play a role and so, whilst this is probably not a case study in effective governance, nor is it one of total disregard for the principles of good governance outlined by the UKDPC.

\section{Acknowledgements}

Thanks to Roger Howard and Nicola Singleton for helpful comments on an earlier version of this paper. Financial support from the UKDPC in the preparation of that earlier piece is also duly acknowledged. There was no conflict of interest.

\section{References}

Advisory Committee on Drug Dependence (1968) Cannabis: Report by the Advisory Committee on Drug Dependence (Wootton Report), London: HMSO.

Advisory Council on the Misuse of Drugs (ACMD) (2002) The Classification of Cannabis under the Misuse of Drugs Act (1971), London: Home Office.

Advisory Council on the Misuse of Drugs (ACMD) (2005) 'Further Consideration of the Classification of Cannabis Under the Misuse of Drugs Act (1971)', London: Home Office. Advisory Council on the Misuse of Drugs (ACMD) (2008) 'Cannabis: Classification and Public Health', London: Home Office.

Advisory Council on the Misuse of Drugs (ACMD) (2009) 'MDMA ('ecstasy'): A Review of its Harms and Classification Under the Misuse of Drugs Act 1971, London: Home Office Advisory Council on the Penal System (1970) Non-custodial and semi-custodial penalties: Report of the Advisory Council on the Penal System (Wootton Report), London: HMSO. Arseneault, L., Cannon, M., Witton, J. and Murray, R. M. (2004) 'Causal Association Between Cannabis and Psychosis: Examination of the Evidence', British Journal of Psychiatry 184(2): 110-117.

Blackman, S. (2010) 'Beyond the Mainstream: Youth Subcultures, Normalisation and Drug Prohibition: The Politics of Contemporary Crisis and Change, British Politics, 5 (3) 337-66 Clarence, E. (2002) 'Technocracy Reinvented: The New Evidence-based Policy Movement', Public Policy and Administration 17(3): 1-11.

Daly, M. and Sampson, S. (2012) Narcomania: How Britain Got Hooked on Drugs, London: Windmill Books

Delanty, G. (1997) Social Science: Beyond Constructivism and Realism, Buckingham: Open University Press

Drugscope (no date) 'Drug laws'

http://www.drugscope.org.uk/resources/drugsearch/drugsearchpages/laws

Dunn, M. (2013) Democracy Under Attack: How the Media Distort Policy and Politics, Bristol: Policy Press

Elwyn, G., Edwards, A., Kinnersely, P. and Grol, R. (2000) Shared decision-making and the concept of equipoise: the competencies of involving patients in healthcare choices, The British Journal of General Practice, 50 (460) 892-899

EMCDDA (2004) 'An Overview of Cannabis Potency in Europe', Lisbon: European Management Centre for Drugs and Drug Addiction

Fergusson, D. M., Horwood, L. J. and Ridder, E. M. (2005) 'Tests of Causal Linkages Between Cannabis Use and Psychotic Symptoms', Addiction 100(3): 354-66.

Fortson, R. (2005) Misuse of Drugs: Offences, Confiscation and Money Laundering, 5th

Edition, London: Sweet and Maxwell. 
Habermas, J. (1975) Legitimation Crisis. London: Heinemann

Hamilton, L., Rubin, J. and Singleton, N. (2012) Characteristics of Good Governance for Drug Policy: Findings from an Expert Consultation, London: UKDPC available online at http://www.ukdpc.org.uk/wp-content/uploads/characteristics-of-good-governance-fordrugpolicy-findings-from-an-expert-consultation.pdf

Head, B.W. (2010) 'Reconsidering evidence-based policy: key issues and challenges', Policy and Society, 29 (2): 77-94.

Henderson, M. (2012) The Geek Manifesto: Why Science Matters, London: Bantam Press Henquet, C., Krabbendam, L., Spauwen, J., Kaplan, C., Lieb, R., Wittchen, H.-U. and van Os, J. (2004) 'Prospective Cohort Study of Cannabis Use, Predisposition for Psychosis, and Psychotic Symptoms in Young People,' British Medical Journal 330(11).

HM Government (2011) 'Principles of scientific advice to government, Department for Business Innovation and Skills available online at http://www.bis.gov.uk/goscience/ principles-of-scientific-advice-to-government

(House of Commons) Home Affairs Committee (2002) 'The Government's Drugs Policy: Is it Working?', London: Home Office.

Kingdon, J. (1984) Agendas, Alternatives, and Public Policies, Boston: Little Brown.

Lacey, N. (2008) The Prisoners' Dilemma: The Political Economy of Punishment in Comparative Perspective, Cambridge: Cambridge University Press

Latour, B. (2004) Politics of Nature: How to Bring the Sciences into Democracy, Cambridge: Cambridge University Press

Levitt, R., Nason, E. and Hallsworth, M. (2006) 'The Evidence-base For the Classification of Drugs', Cambridge: RAND Corporation.

Loader, I. and Sparks, R. (2011) Public Criminology? London: Routledge

MacDonald, R. and Das, A. (2006) 'UK Classification of Drugs of Abuse: An Un-evidencebased Mess', The Lancet 368(9535): 559-61.

MacGregor, S. (2013) 'Barriers to the influence of evidence on policy: Are politicians the problem? Drugs: education, prevention and policy 20 (3) 225-33

Majone, G. (1989) Evidence, Argument and Persuasion in the Policy Process, New Haven: Yale University Press.

May, T., Warburton, H., Turnbull, P. J. and Hough, M. (2002) The Times they are AChanging, York: The Joseph Rowntree Foundation.

Mills, J.H. (2013) Cannabis Nation: Control and Consumption in Britain, 1928-2008, Oxford: Oxford University Press

Monaghan, M. (2008) Appreciating cannabis: the paradox of evidence in evidence-based policy making, Evidence and Policy 4 (2) 209-31

Monaghan, M. (2010) The complexity of evidence: reflections on research utilisation in a heavily politicised policy area, Social Policy and Society, 9 (1) 1-12

Monaghan, M. (2011) Evidence Versus Politics: Exploiting Research in UK Drug Policy Making?, Bristol: Policy Press

Monaghan, M., Pawson, R. and Wicker, K. (2012) The Precautionary Principle and EvidenceBased Policy Making, Evidence and Policy, 8 (2) 171-191

Oakley, A. (2012) 'The strange case of the two Wootton reports: what we can learn about the evidence-policy relationship?, Evidence and Policy, 8 (3) 267-283

Nutt, D. (2010) 'Science and non-science in UK Drug Policy, Addiction, 105 (7) 1154

Nutt, D., King, L. A., Saulsbury, W. and Blakemore, C. (2007) 'Development of a Rational

Scale to Assess the Harm of Drugs of Potential Misuse', The Lancet 369(9566): 1046-1053. 
Nutt, D. King, L.A. and Phillips, L.D. (2010) 'Drug Harms in the UK: A Multi Criteria Decision Analysis', The Lancet, 376 (9752) 1558-1565

Pettit, J. (2001) 'Is criminal justice politically feasible?', Buffalo Criminal Law Review, 5: 24750

Police Foundation (2000) Drugs and the Law: Report of the Inquiry into the Misuse of Drugs Act (1971), London: The Police Foundation

Rittel, H. and Webber, M. (1974) 'Dilemmas in a general theory of planning', Policy Sciences, 4 (155-69), Amsterdam: Elsevier

Royal Society of Arts (RSA) (2007) 'Drugs - Facing the Facts: The Report for the RSA

Commission on Illegal Drugs, Communities and Public Policy', London: The Royal Society for the Encouragement of the Arts, Manufacture and Commerce.

Sabatier, P. A. and Jenkins-Smith, H. C. (eds) (1993) Policy Change and Learning: An

Advocacy Coalition Approach, San Francisco: Westview Press.

Sanderson, I. (2009) 'Intelligent Policy Making for a Complex World: Pragmatism, Evidence and Learning', Political Studies, 57 (4) 699-719

(House of Commons) Science and Technology Committee (2006) 'Drug Classification:

Making a Hash of It?' London: The Stationary Office.

Stevens, A. (2007) 'Survival of the ideas that fit: an evolutionary analogy for the use of evidence in policy', Social Policy and Society 6(1): 25-35.

Stevens, A. (2011) 'Telling policy stories: an ethnographic study of the use of evidence in making policy on drugs and crime, Journal of Social Policy, 40 (2) 237-55

Tieberghien, J. and Decorte, T. (2013) Understanding the science-policy nexus in Belgium: An analysis of the drug policy debate (1996-2003), Drugs: Education, Prevention and Policy, 20 (3) 241-248

Toulmin, S. (2001) Return to Reason, Cambridge: MA, Harvard University Press

van Zwanenberg, P. and Millstone, E. (2005) BSE: Risk, Science and Governance, Oxford:

Oxford University Press.

Warburton, H., May, T. and Hough, M. (2005) Looking the other way: the impact of

reclassifying cannabis on police warnings, arrests and informal action in England and Wales, British Journal of Criminology, 45 (2) 113-128

Weingart, P. (1999) 'Scientific expertise and political accountability: paradoxes of science in politics', Science and Public Policy, 26 (3) 151-61

Weiss, C.H. (1986) 'The many meanings of research utilisation', in M. Bulmer (ed) Social Science and Social Policy, London: Allen Unwin

\section{Notes}

\footnotetext{
i In the 2005 Drugs Act, against the evidence and the opinion of various practitioners, magic mushrooms were placed into class $A$ on the grounds that their active components - psilocin and psilocybin - were of equivalent harm as other class $A$ substances. This has had consequences for use of psilocybins, in particular, in treatment for mental health conditions. ii The 1984 Police and Criminal Evidence Act was also altered so that cannabis assumed a unique status as a class $C$ drug as the police maintained the power of arrest for those caught in possession (Warburton, et al, 2005, p. 116). Additionally, the 2003 Criminal Justice Act
} 
introduced more draconian punishments for supply of class $C$ substances from five years to fourteen years, on a par with those of class B

iii In reality, the dissonance probably started much earlier from around 2003/4 when advice on Ecstasy was rejected as were many of the findings from influential reports such as the Police Foundation

Inquiry (2000). 